\title{
Quais são os sentidos da História? \\ De como alguns jovens latino-americanos avaliaram fatores de mudança na História recente
}

Caroline Pacievitch

\section{SciELO Books / SciELO Livros / SciELO Libros}

PACIEVITCH, C. Quais são os sentidos da História? De como alguns jovens latino-americanos avaliaram fatores de mudança na História recente. In: CERRI, L.F., ed. Os jovens e a História: Brasil e América do Sul [online]. Ponta Grossa: Editora UEPG, 2018, pp. 115-136. ISBN: 978-85-7798-2486. https://doi.org/10.7476/9788577982486.0006.

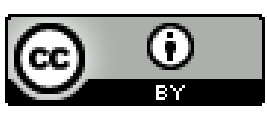

All the contents of this work, except where otherwise noted, is licensed under a Creative Commons Attribution 4.0 International license.

Todo o conteúdo deste trabalho, exceto quando houver ressalva, é publicado sob a licença $\underline{\text { Creative Commons }}$ Atribição 4.0.

Todo el contenido de esta obra, excepto donde se indique lo contrario, está bajo licencia de la licencia $\underline{\text { Creative }}$ Commons Reconocimento 4.0. 


\section{QUAIS SÃO OS SENTIDOS DA HISTÓRIA? DE COMO ALGUNS JOVENS LATINO-AMERICANOS AVALIARAM FATORES DE MUDANÇA NA HISTÓRIA RECENTE}

Caroline Pacievitch

Este capítulo apresenta possibilidades de análise com dados do projeto de pesquisa Jovens e a História, explorando alguns fatores de mudança na História recente, avaliados por estudantes e seus professores. O entendimento da escala Likert, aqui, ocorreu conforme as orientações expostas em Barom (2017), em que os resultados entre -1 e +1 indicam movimento da neutralidade à concordância/discordância, enquanto resultados ligados a +1 e +2 indicam níveis progressivos de concordância, ocorrendo o inverso em resultados próximos a -1 e -2. Segundo Cerri (2016), os dados quantitativos resultantes desses questionários não representam uma amostra probabilística. Entretanto, "[...] contém informações riquíssimas sobre a realidade do ensino e da aprendizagem de História na América do Sul [...] [cujos] resultados são igualmente significativos para pensar as condições e o estado atual do ensino e da aprendizagem, assim como elementos da cultura na qual estão imersos professores, alunos e aulas" (CERRI, 2016, p. 147).

Para os fins deste capítulo, as respostas de professores e de estudantes foram cruzadas com as diferenças por país, conforme convicção política (professores) e por interesse pela política (estudantes). As descrições aqui presentes são orientadas pelos seguintes questionamentos: quais fatores são os favoritos para professores e para alunos? Em quais fatores discordam? Em quais países há maior e menor proximidade entre as opiniões de estudantes e professores?

A intenção inicial é, portanto, verificar quais são as razões mais recorrentes evocadas para explicar as mudanças do passado e do futuro, questionando se as semelhanças e diferenças poderiam ser relacionadas a algum tipo de historiografia e/ou de tendência de ensino de História específicos, e que narrativas de passado (causalidades) e expectativas de futuro podem ser inferidas; isto é, questionar que sentidos para a História são delineados nesse conjunto de dados. É possível refletir, ainda, se as razões 
mais e menos recorrentes oferecem indícios sobre a visão desses jovens e dos professores sobre seu papel como agentes da História.

As primeiras seções deste capítulo apresentam dados gerais e seus cruzamentos simples. Ao final, pretende-se analisar as constatações a partir da ideia de sentido histórico conforme Jörn Rüsen (2015), tentando contribuir para o entendimento de aspectos do pensamento histórico de estudantes e de seus professores de História, no que se refere à explicação histórica e ao sentido histórico.

\section{PANORAMA}

Nesta seção apresenta-se um panorama geral dos dados selecionados, alternando as constatações obtidas entre os estudantes e seus professores e arriscando alguns cruzamentos. Na tabela 1 encontram-se os resultados obtidos que orientam as análises. Os números parecem refletir a ideia de que as inovações no campo da tecnologia e das invenções, junto com interesses econômicos e conflitos sociais foram os fatores mais relevantes de mudança, na avaliação dos estudantes. Fatores de tipo individual e coletivo encontramse tanto entre os mais quanto nos menos relevantes, embora priorizem, sem dúvida, questões conjunturais, sendo os cientistas e engenheiros os únicos indivíduos que aparecem como fatores relevantes, à frente dos movimentos e conflitos sociais. Temas que, atualmente, são muito relevantes no debate político mundial, como líderes religiosos e migrações não eram vistos como relevantes quando esses jovens responderam à questão.

Tabela 1 - Comparação de médias* das respostas de professores e estudantes em cada amostra nacional à questão Que influência você acha que tiveram os seguintes fatores na mudança da vida das pessoas desde 1970 até hoje?

\begin{tabular}{|c|c|c|c|c|c|c|c|c|c|c|}
\hline & 吾 & 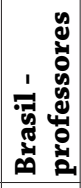 & 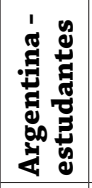 & 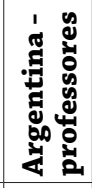 & 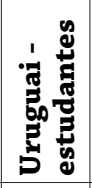 & 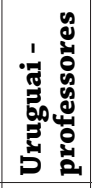 & 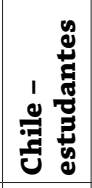 & 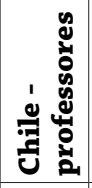 & 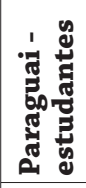 & 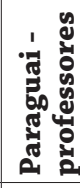 \\
\hline $\begin{array}{l}\text { 19a. Invenções } \\
\text { técnicas e } \\
\text { mecanização }\end{array}$ & 1,12 & 1,56 & 0,91 & 0,86 & 0,98 & 0,57 & 1,01 & 1,38 & 0,67 & 1,00 \\
\hline
\end{tabular}




\begin{tabular}{|c|c|c|c|c|c|c|c|c|c|c|}
\hline & 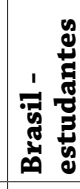 & 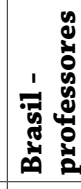 & 量 & 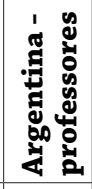 & . & 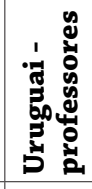 & 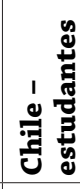 & 㝴 & 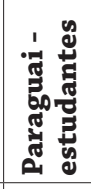 & 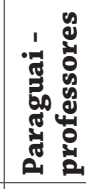 \\
\hline $\begin{array}{l}\text { 19b. Movimentos e } \\
\text { conflitos sociais }\end{array}$ & 0,69 & 1,17 & 0,69 & 1,34 & 0,72 & 1,38 & 1,11 & 1,46 & 0,56 & 1,13 \\
\hline $\begin{array}{l}\text { 19c. Reis, } \\
\text { presidentes e } \\
\text { personagens } \\
\text { politicamente } \\
\text { importantes no } \\
\text { poder }\end{array}$ & 0,49 & 0,26 & 0,38 & $-0,69$ & 0,39 & $-0,88$ & 0,79 & $-0,46$ & 0,60 & $-0,25$ \\
\hline $\begin{array}{l}\text { 19d. Reformas } \\
\text { políticas }\end{array}$ & 0,64 & 0,76 & 0,57 & 0,75 & 0,72 & 0,50 & 0,84 & 0,85 & 0,54 & 0,88 \\
\hline $\begin{array}{l}\text { 19e. Fundadores de } \\
\text { religiões e chefes } \\
\text { religiosos }\end{array}$ & 0,24 & 0,21 & $-0,11$ & $-0,68$ & $-0,01$ & $-0,75$ & 0,22 & 0,15 & 0,51 & 0,25 \\
\hline $\begin{array}{l}\text { 19f. } \\
\text { Desenvolvimento } \\
\text { da ciência e do } \\
\text { conhecimento }\end{array}$ & 1,15 & 1,53 & 1,04 & 0,91 & 1,20 & 0,88 & 1,25 & 1,46 & 1,02 & 1,13 \\
\hline $\begin{array}{l}\text { 19g. Guerras e } \\
\text { conflitos }\end{array}$ & 0,53 & 0,88 & 0,74 & 0,95 & 0,79 & 1,00 & 1,10 & 1,31 & 0,75 & 0,75 \\
\hline $\begin{array}{l}\text { 19h. Interesses } \\
\text { econômicos e } \\
\text { concorrência } \\
\text { econômica }\end{array}$ & 0,78 & 1,38 & 0,71 & 1,27 & 0,70 & 1,75 & 0,90 & 1,69 & 0,88 & 1,25 \\
\hline $\begin{array}{l}\text { 19i. Filósofos, } \\
\text { pensadores e pessoas } \\
\text { instruídas }\end{array}$ & 0,25 & 0,23 & 0,17 & 0,04 & $-0,07$ & $-0,13$ & 0,55 & 0,46 & 0,62 & 0,63 \\
\hline $\begin{array}{l}\text { 19j. Revoluções } \\
\text { políticas }\end{array}$ & 0,49 & 0,61 & 0,53 & 0,69 & 0,62 & 1,00 & 0,87 & 1,23 & 0,47 & 0,75 \\
\hline $\begin{array}{l}\text { 19k. Problemas } \\
\text { ambientais }\end{array}$ & 0,70 & 1,09 & 0,42 & 0,11 & 0,15 & $-0,88$ & 0,61 & 1,08 & 0,63 & 1,00 \\
\hline 191. Migrações & 0,39 & 0,72 & 0,37 & 0,54 & 0,24 & 0,13 & 0,51 & 1,23 & 0,61 & 1,50 \\
\hline $\begin{array}{l}19 \mathrm{~m} \text {. Organização } \\
\text { dos trabalhadores }\end{array}$ & 0,49 & 0,83 & 0,34 & 0,58 & 0,36 & 0,63 & 0,69 & 0,92 & 0,39 & 0,63 \\
\hline 19n. Esforço pessoal & 0,36 & 0,49 & 0,18 & $-0,34$ & 0,01 & $-0,25$ & 0,31 & 0,08 & 0,60 & 0,50 \\
\hline $\begin{array}{l}\text { 19o. Cientistas e } \\
\text { engenheiros }\end{array}$ & 0,89 & 0,82 & 0,50 & 0,00 & 0,42 & $-0,25$ & 0,68 & 0,38 & 0,68 & 0,75 \\
\hline
\end{tabular}

Fonte: Dados do Projeto Jovens e a História (2013). Elaboração da autora.

* Médias aritméticas das respostas obtidas pela transformação da escala Likert na seguinte escala numérica: Muito pouca = $-2 ;$ Pouca $=-1 ;$ Média $=0 ;$ Grande = $1 ;$ Muito grande $=2$. 
Entre os professores, como se observa, as tendências são muito parecidas. A principal diferença entre estudantes e professores encontra-se na intensidade das respostas, pois os docentes afastam-se mais da neutralidade do que os jovens. Estes também atribuem maior importância para fatores individuais, como Cientistas e engenheiros; Esforço pessoal; Líderes religiosos e Personagens politicamente importantes no poder. Os jovens atribuem muito menos importância aos Interesses econômicos e à concorrência econômica, e aos movimentos e conflitos sociais do que seus professores, em geral.

$\mathrm{Na}$ Tabela 2, o olhar dirige-se para as tendências de futuro.

Tabela 2 - Comparação de médias* das respostas de professores e estudantes em cada amostra nacional à questão Que influência você acha que terão os seguintes fatores na mudança da vida das pessoas de agora até 2050?

\begin{tabular}{|c|c|c|c|c|c|c|c|c|c|c|}
\hline & 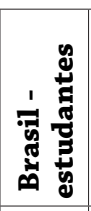 & 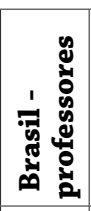 & 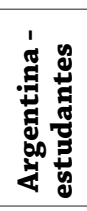 & 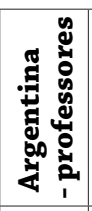 & 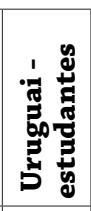 & 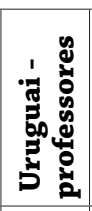 & 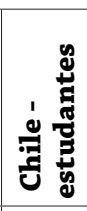 & 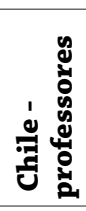 & 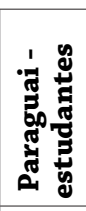 & 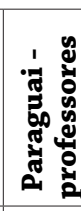 \\
\hline $\begin{array}{l}\text { 20a. Invenções } \\
\text { técnicas e } \\
\text { mecanização }\end{array}$ & 1,34 & 1,63 & 1,05 & 1,29 & 1,10 & 1,25 & 1,03 & 1,54 & 1,00 & 1,63 \\
\hline $\begin{array}{l}\text { 20b. Movimentos e } \\
\text { conflitos sociais }\end{array}$ & 0,53 & 1,10 & 0,64 & 1,27 & 0,67 & 1,00 & 1,07 & 1,46 & 0,57 & 1,38 \\
\hline $\begin{array}{l}\text { 20c. Reis, } \\
\text { presidentes e } \\
\text { personagens } \\
\text { politicamente } \\
\text { importantes no } \\
\text { poder }\end{array}$ & 0,15 & 0,04 & 0,05 & $-1,00$ & 0,02 & $-1,38$ & 0,22 & $-0,69$ & 0,30 & $-0,50$ \\
\hline $\begin{array}{l}\text { 20d. Reformas } \\
\text { políticas }\end{array}$ & 0,46 & 0,69 & 0,51 & 0,68 & 0,57 & 0,63 & 0,52 & 1,00 & 0,65 & 1,14 \\
\hline $\begin{array}{l}20 \text { e. Fundadores de } \\
\text { religiões e chefes } \\
\text { religiosos }\end{array}$ & $-0,05$ & 0,11 & $-0,46$ & $-0,76$ & $-0,37$ & $-0,88$ & $-0,34$ & $-0,23$ & 0,16 & 0,13 \\
\hline $\begin{array}{l}20 f . \\
\text { Desenvolvimento } \\
\text { da ciência e do } \\
\text { conhecimento }\end{array}$ & 1,31 & 1,66 & 1,14 & 1,20 & 1,23 & 1,50 & 1,20 & 1,77 & 1,15 & 1,50 \\
\hline $\begin{array}{l}\text { 20g. Guerras e } \\
\text { conflitos }\end{array}$ & 0,29 & 0,90 & 0,60 & 0,86 & 0,52 & 0,63 & 0,84 & 1,38 & 0,57 & 1,25 \\
\hline $\begin{array}{l}\text { 20h. Interesses } \\
\text { econômicos e } \\
\text { concorrência } \\
\text { econômica }\end{array}$ & 1,00 & 1,45 & 0,87 & 1,34 & 0,86 & 1,63 & 1,07 & 1,77 & 1,07 & 1,63 \\
\hline
\end{tabular}




\begin{tabular}{|c|c|c|c|c|c|c|c|c|c|c|}
\hline & 宽 & 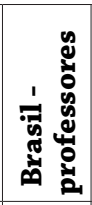 & 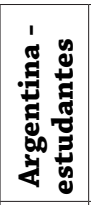 & 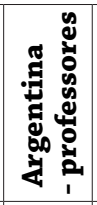 & 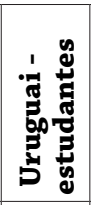 & 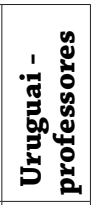 & & 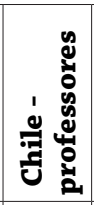 & 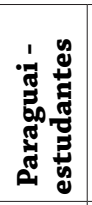 & 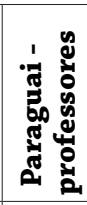 \\
\hline $\begin{array}{l}\text { 20i Filósofos, } \\
\text { pensadores e } \\
\text { pessoas instruídas }\end{array}$ & 0,00 & 0,34 & $-0,12$ & $-0,16$ & $-0,30$ & $-0,25$ & 0,22 & 0,23 & 0,15 & 0,63 \\
\hline $\begin{array}{l}\text { 20j. Revoluções } \\
\text { políticas }\end{array}$ & 0,37 & 0,72 & 0,41 & 0,64 & 0,39 & 0,00 & 0,75 & 1,38 & 0,29 & 1,14 \\
\hline $\begin{array}{l}\text { 20k. Problemas } \\
\text { ambientais }\end{array}$ & 1,14 & 1,64 & 1,08 & 0,96 & 0,63 & 0,00 & 1,02 & 1,77 & 0,94 & 1,63 \\
\hline 201. Migrações & $0, \pm 0$ & 0,85 & 0,13 & 0,49 & 0,04 & 0,25 & 0,30 & 1,23 & 0,44 & 1,63 \\
\hline $\begin{array}{l}20 \mathrm{~m} \text {. Organização } \\
\text { dos trabalhadores }\end{array}$ & 0,41 & 0,79 & 0,24 & 0,73 & 0,18 & 0,88 & 0,57 & 1,15 & 0,31 & 1,13 \\
\hline $\begin{array}{l}\text { 20n. Esforço } \\
\text { pessoal }\end{array}$ & 0,45 & 0,75 & 0,18 & $-0,18$ & 0,30 & 0,63 & 0,38 & 0,38 & 0,61 & 1,13 \\
\hline $\begin{array}{l}\text { 20o. Cientistas e } \\
\text { engenheiros }\end{array}$ & 1,12 & 1,06 & 0,66 & 0,26 & 0,92 & 0,63 & 0,79 & 0,69 & 0,81 & 1,13 \\
\hline
\end{tabular}

Fonte: Dados do Projeto Jovens e a História (2013). Elaboração da autora.

* Médias aritméticas das respostas obtidas pela transformação da escala Likert na seguinte escala numérica: Muito pouca = $-2 ;$ Pouca $=-1 ;$ Média $=0 ;$ Grande $=1 ;$ Muito grande $=2$.

Com relação aos fatores de mudança para o futuro, os estudantes permanecem basicamente com as mesmas perspectivas, com a diferença de que as questões ambientais tornam-se mais prementes. Inovações técnicas, cientistas e engenheiros, ciência e conhecimento continuam sendo os fatores mais mencionados, seguidos de perto pelos interesses econômicos. Em um lugar intermediário encontram-se novamente os Movimentos e conflitos sociais, as Reformas políticas, Guerras e conflitos e Revoluções políticas. Esforço pessoal e organização dos trabalhadores recebem notações próximas da neutralidade, assim como Migrações e Reis, presidentes e personagens politicamente importantes no poder. A grande diferença em relação às perspectivas de passado encontra-se na presença de números negativos atribuídos aos fundadores de religiões e chefes religiosos e aos Filósofos, pensadores e pessoas instruídas. Como visto, apenas em alguns países essas médias chegavam a números negativos. É tentador questionar se, após a intensa divulgação da crise de refugiados na Europa e a intensificação de atos de grupos baseados em fundamentalismo religioso, os 
estudantes seguiriam valorizando da mesma forma o poder das religiões e das migrações como fatores de mudança.

Em síntese, na comparação geral entre as expectativas para o futuro e levantamento de causas no passado, nota-se que os jovens estavam mais confiantes nos seguintes fatores de mudança no futuro: as invenções técnicas e a mecanização, a ciência e o conhecimento, os interesses econômicos, os problemas ambientais (como visto, os que mais cresceram), o esforço pessoal e cientistas e engenheiros. Todos os demais diminuíram, e líderes religiosos e filósofos e pensadores atingiram números negativos. As diferenças entre estudantes dos quatro países são mais intensas nas análises que fazem sobre o passado do que sobre o futuro. Ao indicar fatores de mudança para o futuro eles se mostram, em geral, mais prudentes, atingindo números mais próximos da neutralidade.

Com relação aos professores, também se notam poucas alterações entre a análise de passado e as perspectivas de futuro. O mesmo movimento percebido entre os jovens - crescimento dos Problemas ambientais como fatores de mudança - aparece nas respostas dos docentes. Ciência e conhecimento, Inovações técnicas e Interesses econômicos seguem os favoritos, mas agora seguidos de Problemas ambientais e de Movimentos e conflitos sociais. Este último, como visto, é o que tem diferenciado as respostas de estudantes e de professores. Outra semelhança em relação aos estudantes são as médias negativas para Reis, presidentes e personagens politicamente importantes e Fundadores de religiões e chefes religiosos, que já tinham médias negativas nas respostas sobre o passado, mas que se aprofundaram para o futuro. Guerras e conflitos, Organização dos trabalhadores, Migrações, Revoluções e reformas políticas continuam com valor intermediário. Com valores muito próximos a zero (além de personagens políticos e religiosos) encontram-se o Esforço pessoal e Filósofos, pensadores e pessoas instruídas. Tanto entre professores quanto entre estudantes há maior valorização de processos coletivos do que individuais (como visto, no Brasil essa diferença é menor do que nos outros países), à exceção dos cientistas, que estão ora em posições intermediárias, ora como fatores favoritos de mudança. Tais constatações permitem pensar que professores e jovens entendem esse intervalo de 80 anos como História (ou futuro) 
próximos, em que não se notam grandes rupturas em relação aos fatores que explicam mudanças.

\section{POSSIBILIDADES DE ANÁLISE}

Dessas constatações iniciais desenham-se possibilidades de análise. A primeira foi pensar em cruzamentos em relação às convicções políticas dos docentes; outras, sobre os conteúdos favoritos dos estudantes. Antes disso, porém, outras três questões para os estudantes chamaram a atenção, pelo potencial de correlação com os fatores de mudança apontados nessas duas primeiras: como você pensa que era a vida do seu país há 40 anos? Como você pensa que será a vida do seu país em 40 anos? Como você acha que será a sua vida daqui a 40 anos? Não há equivalente, no questionário de professores, a essas perguntas. Mesmo assim, considera-se importante explorar essas possibilidades entre os jovens, tendo em vista seu potencial para perseguir as questões ligadas à agência histórica e a sentido histórico.

O gráfico 1 ilustra as respostas à primeira pergunta, em que os participantes acreditam que o que melhor caracterizava a vida do seu país há 40 anos foram os conflitos políticos. É interessante, pois esse não foi um dos fatores de mudança mais fortes apontados por eles nas questões anteriores. Evidentemente, não havia a opção de escolha do tipo agitada por diversas inovações tecnológicas. Além disso, essa pergunta se referia à vida no país, enquanto a anterior tratava do mundo. Os jovens também acreditam que, depois dos conflitos políticos, o que mais caracterizava a vida no país eram os problemas entre ricos e pobres e, próximo da neutralidade, a situação de exploração por um país estrangeiro e a poluição. Os estudantes discordam de que o país era Próspero e rico, Pacífico ou Democrático.

Quando são convidados a projetar o futuro do país nos próximos 40 anos (Gráfico 2), a poluição torna-se o maior problema, saltando de -0,08 para 0,95 . O país seguirá agitado por conflitos políticos e entre ricos e pobres, mas há maior segurança quanto ao fato de que será uma democracia (hoje seria diferente?). Os estudantes têm dúvidas se a sociedade será Próspera e rica, e duvidam de que seja Pacífica ou Explorada por um país estrangeiro. Efetivamente, estes três últimos fatores estão próximos da neutralidade. 
Gráfico 1 - Comparação das médias * das respostas dos estudantes à questão Como você pensa que era a vida do seu país há 40 anos?

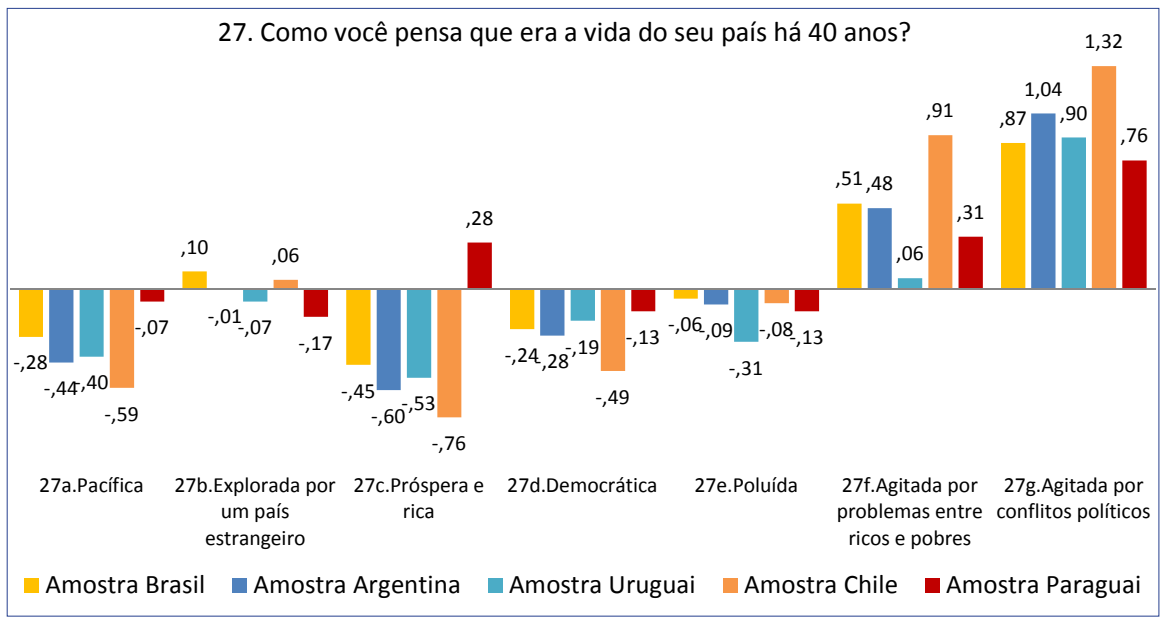

Fonte: Projeto Jovens e a História (2013). Elaboração da autora.

* Médias aritméticas das respostas obtidas pela transformação da escala Likert na seguinte escala numérica: Muito dificilmente $=-2$; Dificilmente $=-1$; Talvez $=0$; Provavelmente $=1$; Muito provavelmente $=2$.

Gráfico 2 - Comparação das médias * das respostas dos estudantes à questão Como você acha que será a vida do seu país daqui a 40 anos?

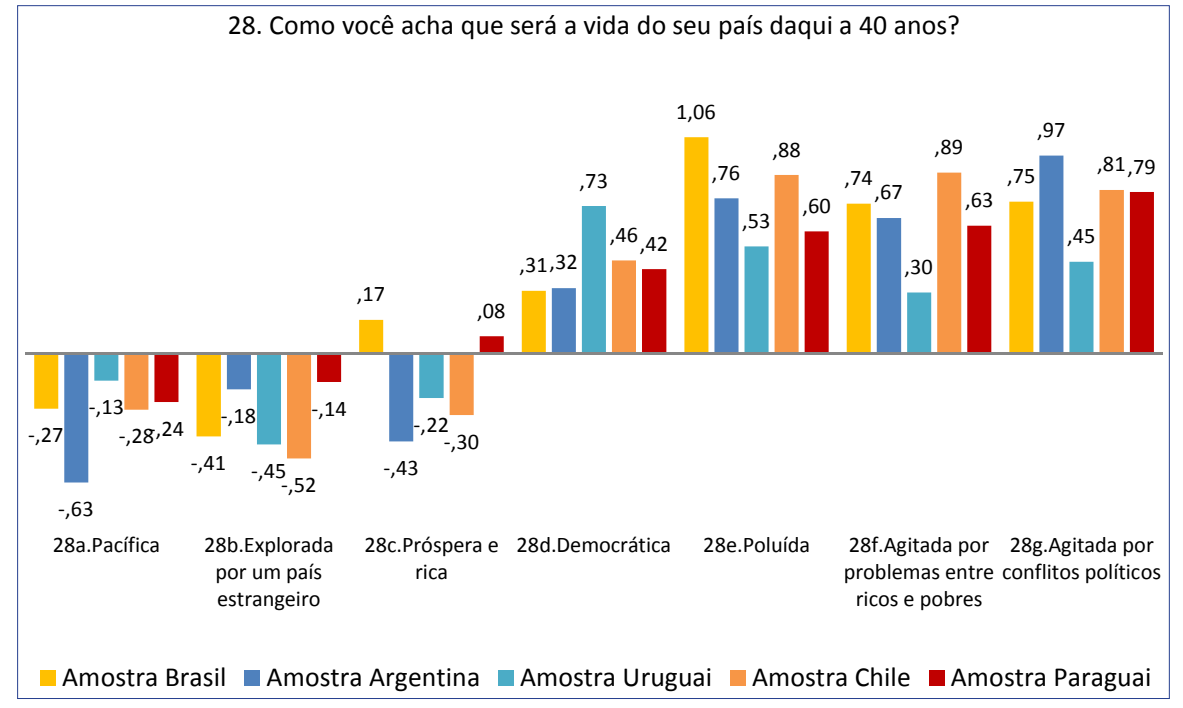

Fonte: Projeto Jovens e a História (2013). Elaboração da autora.

* Médias aritméticas das respostas obtidas pela transformação da escala Likert na seguinte escala numérica: Muito dificilmente $=-2$; Dificilmente $=-1$; Talvez $=0$; Provavelmente $=1$; Muito provavelmente $=2$. 
Comparando as interpretações de passado entre estudantes de Brasil, Argentina, Uruguai, Chile e Paraguai, nota-se que os estudantes chilenos se destacam pela maior intensidade de suas respostas; isto é, afastam-se mais do que os outros da neutralidade, principalmente em relação à dúvida sobre a existência de Paz, de Prosperidade e de Democracia. Também são mais incisivos que os demais ao acreditar que seu país era agitado por Conflitos políticos e entre ricos e pobres. Os estudantes paraguaios e os brasileiros são os que menos afirmam que seu país atravessava conflitos políticos há 40 anos. Os paraguaios são os únicos que apresentam valores positivos (embora bem próximos de zero) para o fato de que seu país era uma sociedade próspera e rica há 40 anos.

Quanto às projeções de futuro, entre os estudantes argentinos há os maiores níveis de pessimismo. Duvidam que seu país seja pacífico, não projetam prosperidade ou riqueza e estão mais seguros do que os demais de que será agitada por conflitos políticos. Os estudantes brasileiros aproximam-se dos demais em todos os casos, exceto em um: é o único país a apresentar valor positivo no fator Prosperidade e riqueza. Obviamente, é um número pequeno, mais próximo da neutralidade, mas, na comparação com os demais, é um destaque interessante. Os uruguaios parecem ser os mais otimistas de todos no que se refere à estabilidade democrática, à poluição e à existência de conflitos entre ricos e pobres ou políticos. Já os chilenos apenas duvidam mais do que os outros de que o Chile pode vir a ser explorado por um país estrangeiro nos próximos 40 anos.

$O$ fato de argentinos e uruguaios serem os mais pessimistas e os mais otimistas, respectivamente, pode sinalizar conexões entre as compreensões desses jovens e o clima político vivido em seus países no período em que os questionários foram aplicados. Mas indica, principalmente, a importância de replicar investigações dessa envergadura ao longo do tempo, tendo em vista as mudanças políticas vividas pela Argentina após a eleição de Macri. Além disso, teria sido extremamente interessante comparar essas respostas com as dos docentes.

Uma possibilidade de conexão mostra-se com a questão $\mathrm{n}^{0} 29$, sobre como os jovens projetam sua própria vida daqui a 40 anos. Tendo em 
vista que apresentam baixas expectativas sobre a estabilidade política e social de seu país, seriam, também, pessimistas em relação a seu próprio futuro? Ao observar o gráfico 3, parece que os jovens estão medianamente seguros de que terão uma boa vida, em que haverá, principalmente, bons amigos, trabalho prazeroso, e uma família feliz e harmoniosa, com pouca participação política. Os jovens também creem que terão tempo livre para o lazer, rendimentos elevados e liberdade política e individual.

Gráfico 3 - Comparação das médias * das respostas dos estudantes à questão Como você pensa que será a sua vida daqui a 40 anos?

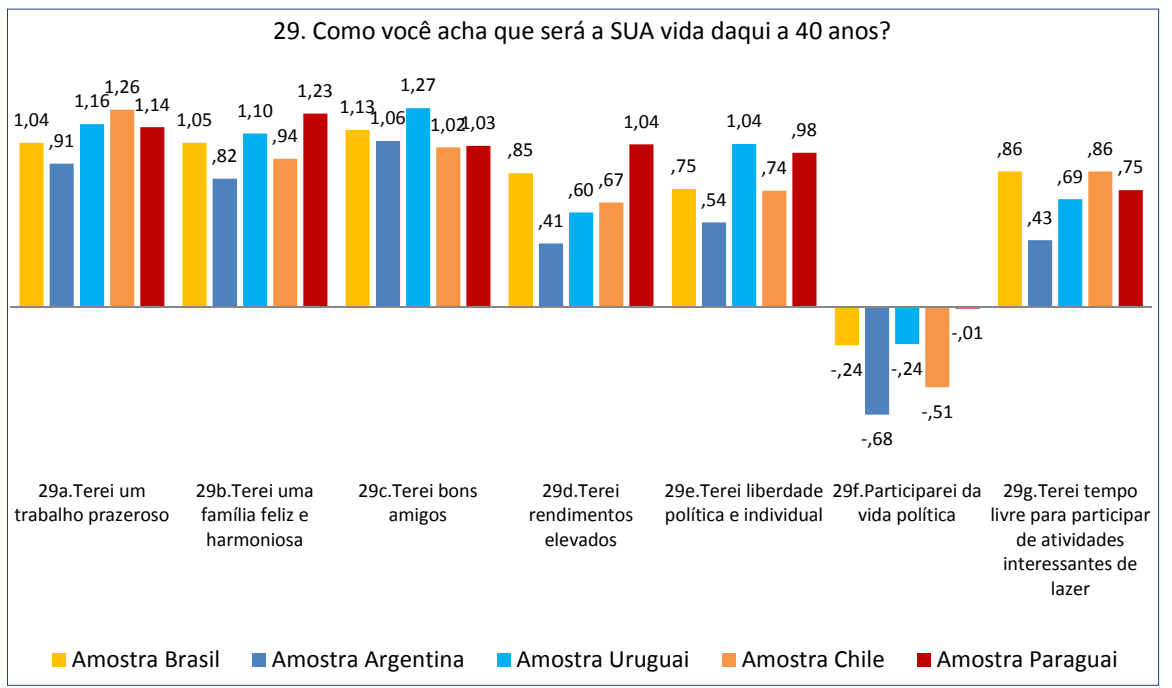

Fonte: Projeto Jovens e a História (2013). Elaboração da autora.

* Médias aritméticas das respostas obtidas pela transformação da escala Likert na seguinte escala numérica: Muito dificilmente $=-2$; Dificilmente $=-1$; Talvez $=0$; Provavelmente $=1$; Muito provavelmente $=2$.

Na comparação entre países, conforme apresenta o Gráfico 3, novamente entre os argentinos há as médias mais baixas. Assim, apesar de projetarem um futuro positivo para si próprios, são mais prudentes do que os demais em todos os aspectos, à exceção dos bons amigos, em que os chilenos são os menos convencidos. Os argentinos duvidam principalmente de que poderão ter rendimentos elevados, oportunidades de lazer e participação política. Os uruguaios novamente estão entre os mais confiantes em seu futuro, à exceção da fruição de rendimentos elevados e de lazer, destacando-se otimismo quanto à liberdade política e individual e seu 
interesse pela participação política que, embora seja negativo, empata com os jovens brasileiros, por serem os que mais se aproximam da neutralidade, sendo os argentinos e chilenos os, aparentemente, menos interessados. Os paraguaios parecem ser os mais confiantes na possibilidade de liberdade e de participação política.

Neste sentido, apesar de, para o conjunto de seus países serem mais pessimistas do que em relação à vida pessoal, seus projetos de vida refletem a interpretação geral que fazem da trajetória de seu país em um intervalo de 80 anos. Entretanto, é difícil conectar com as questões em análise no tópico anterior.

\section{SERIA A POLÍTICA UMA VARIÁVEL IMPORTANTE?}

Uma possibilidade de análise utilizando os dados dos professores é com relação a suas opções políticas na hora do voto, expressas nos gráficos 4 e 5 . O questionário permitiu fazer o cruzamento entre as opções docentes nas eleições e os fatores de mudança no tempo mais conectados. Assim, isolaram-se dados de professores brasileiros que votam à direita e centro-direita, ao centro e à esquerda e centro-esquerda, cruzando com as respostas às questões sobre fatores de mudança no passado e no futuro.

Comparando as respostas, nota-se que predomina a concordância entre os docentes, independentemente de sua convicção política para o voto. Apenas em alguns aspectos há diferenças significativas, tanto para o passado quanto para o futuro: na importância atribuída a líderes e movimentos religiosos, ao esforço pessoal e à importância de reis e personagens políticos no poder. Nesses casos, professores que preferem partidos de direita estão ligeiramente acima dos demais. Apesar de terem maior tendência a valorizar ações individuais, os professores que votam à direita e centro-direita são os que menos confiam em cientistas e engenheiros como fatores de mudança, tanto para o passado quanto para o futuro. As respostas desses docentes são estáveis, quando se comparam opções feitas para o futuro e para o passado, embora se tornem menos confiantes quanto ao papel dos líderes políticos, religiosos e filósofos, bem como das guerras, revoluções políticas e migrações para o futuro. Pensam, ainda, que os movimentos de 
trabalhadores, o esforço pessoal, os problemas ambientais, a ciência e as invenções terão maior força no futuro do que no passado.

Gráfico 4 - Professores brasileiros. Escolha eleitoral e fatores de mudança no passado

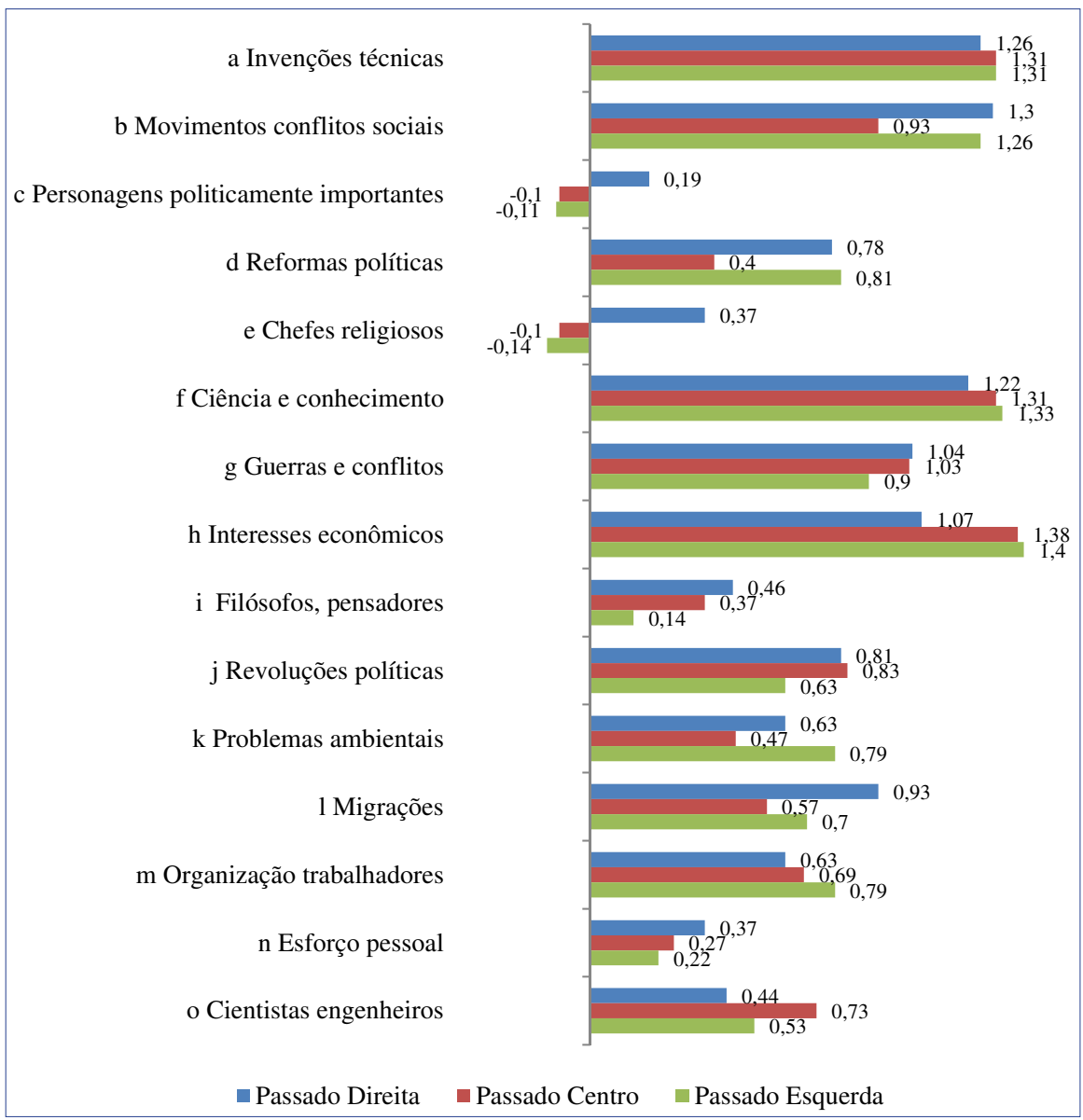

Fonte: Projeto Jovens e a História. 2012.

Quanto aos professores que afirmam preferir partidos de centro, comparando a valorização atribuída aos fatores para o passado e o futuro, a tendência segue a média geral: mostram-se mais seguros quanto ao valor da ciência, das invenções, dos cientistas e engenheiros, dos problemas ambientais, dos movimentos sociais e dos interesses econômicos para mudanças no futuro em relação ao passado. Também acreditam que o esforço pessoal 
será um fator mais importante no futuro do que no passado. Estão ainda menos convencidos do poder de reis e personagens políticos importantes, de filósofos e pensadores, de líderes religiosos, de guerras, das revoluções e das migrações como fatores de mudança para o futuro.

Gráfico 5 - Professores brasileiros. Escolha eleitoral e fatores de mudança no futuro

a Invenções técnicas
b Movimentos conflitos sociais
c Personagens politicamente importantes $0,0,290,15$
d Reformas políticas
e Chefes religiosos
f Ciência e conhecimento
g Guerras e conflitos
h Interesses econômicos
i Filósofos, pensadores
j Revoluções políticas
k Problemas ambientais
1 Migrações

Fonte: Projeto Jovens e a História. 2012.

O panorama comparativo para os professores que afirmam votar em partidos de esquerda e centro-esquerda é basicamente o mesmo que os de centro, com a diferença de que estão ligeiramente menos convencidos do poder dos movimentos sociais e das reformas políticas, mas continuam bastante confiantes em ciência, invenções, engenheiros, esforço pessoal, movimentos dos trabalhadores, revoluções políticas, guerras, problemas ambientais e interesses econômicos. Assim como os demais, duvidam que 
reis e personagens políticos importantes e líderes religiosos sejam fatores significativos de mudança, tanto no passado quanto no futuro (mais intensamente no futuro do que no passado).

Essas constatações, conectadas com pesquisas anteriores (PACIEVITCH, 2014), ajudam a demonstrar que convicção ou escolha política não é um fator de influência significativa sobre as interpretações e opiniões docentes sobre os fatores de mudança histórica no passado recente e no futuro próximo, embora possam ser percebidos alguns elementos de diferenciação. Mesmo assim, o esforço pessoal, fator que poderia ser reconhecido como tipicamente liberal ou de direita, ligado à meritocracia, é valorizado de forma semelhante nos três grupos de docentes. Isto poderia se conectar ao próprio papel de professor, que estimula os estudantes e crê que seu esforço pessoal possa fazer a diferença em suas vidas? Ou se trata de um reflexo de perspectivas mais esperançosas sobre o futuro e a democracia, em que desigualdades cristalizadas já não são fatores tão importantes de impedimento de ascensão social? Quiçá, os casos de professores ativistas, no sentido atribuído por Soares (2008) e criticado por Paim (2005), não se expliquem por suas convicções políticas, mas por fragilidades na formação historiográfica, didática e, por que não, ética, não se explicando apenas pela opção na hora do voto.

Aos estudantes não se questionou sobre escolhas eleitorais, mas sobre o quanto consideravam a política um tema importante. As respostas foram divididas em três grupos: aqueles que possuíam interesse e grande interesse por política, os que possuíam algum interesse por política e os que possuíam pequeno ou muito pequeno interesse por política. Cada grupo foi cruzado com as respostas dadas aos fatores de mudança para o passado e para o futuro, a fim de constatar semelhanças ou diferenças.

Todos os três grupos de estudantes, em geral, acompanham as médias para as questões. A curva de valores mostra que é descendente ou ascendente, em geral, nos mesmos aspectos. Os estudantes que possuem grande e algum interesse por política apresentam valorizações com números muito semelhantes entre si. Já os que possuem pouco ou nenhum interesse por política apresentam médias bem mais baixas do que os demais. 
Gráfico 6 - Estudantes. Interesse por política x fatores de mudança no passado

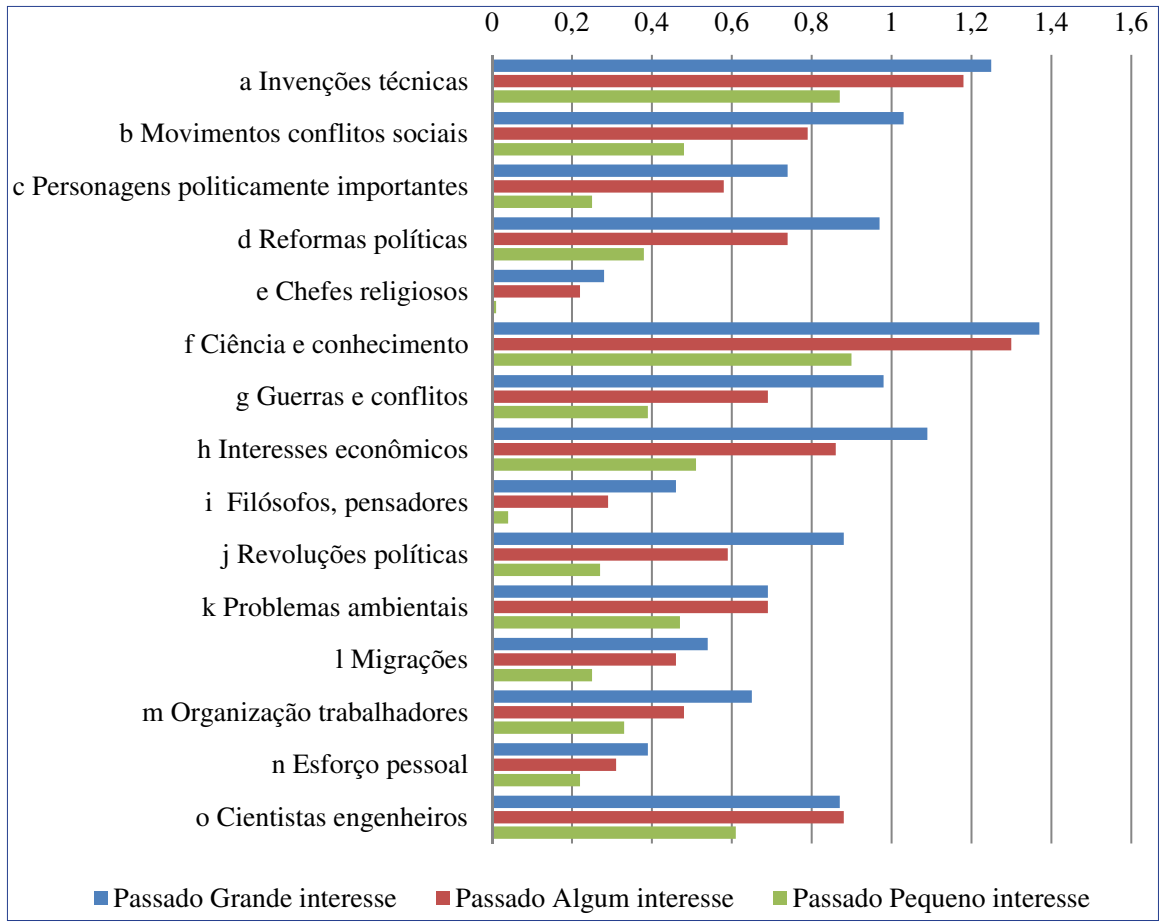

Fonte: Projeto Jovens e a História. 2013.

Os valores para passado e para futuro não se alteram significativamente, mas se nota o mesmo movimento entre os estudantes que afirmam ter pequeno ou nenhum interesse por política: as médias são bem menores do que os que afirmam ter grande ou algum interesse.

De maneira geral, todos seguem a média, mas os estudantes que têm grande ou algum interesse por política são mais incisivos em sua avaliação do que os que não possuem interesse. Seria importante fazer cruzamentos com todas as perguntas, para ver se é uma tendência. Além disso, poderse-ia tentar localizar quem são os jovens que afirmam não possuir interesse por política. Em quais escolas se concentram? Quais são seus conteúdos favoritos? Qual seu posicionamento sobre temas sensíveis? Apesar da dificuldade de refletir sobre convicções políticas entre pessoas tão jovens, esse pode ser um indício importante para a reflexão de professores de História. 
Gráfico 7 - Estudantes. Interesse por política x fatores de mudança no passado

$$
\begin{array}{lllllllllll}
-0,4 & -0,2 & 0 & 0,2 & 0,4 & 0,6 & 0,8 & 1 & 1,2 & 1,4 & 1,6
\end{array}
$$

b Movimentos conflitos sociais

c Personagens politicamente importantes

d Reformas políticas

e Chefes religiosos

f Ciência e conhecimento

g Guerras e conflitos

h Interesses econômicos

i Filósofos, pensadores

j Revoluções políticas

$\mathrm{k}$ Problemas ambientais

1 Migrações

m Organização trabalhadores

$\mathrm{n}$ Esforço pessoal

o Cientistas engenheiros

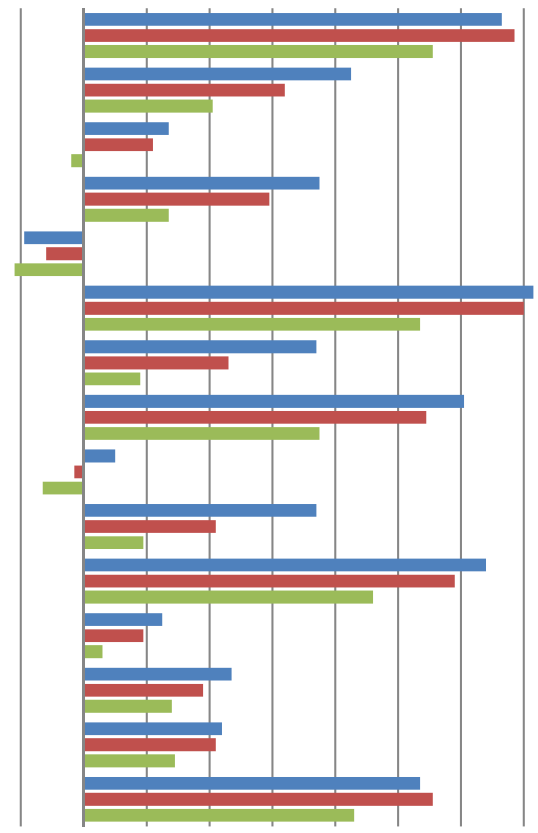

$\square$ Futuro Grande interesse $\quad$ Futuro Algum interesse $\quad$ Futuro Pequeno interesse

Fonte: Projeto Jovens e a História. 2013.

\section{SOBRE A AGÊNCIA HISTÓRICA E OS SENTIDOS HISTÓRICOS}

O conjunto de dados apresentados neste texto permite concluir que os fatores favoritos de mudança variam pouco em relação a passado-futuro, ao país, em relação a professores e alunos e às escolhas políticas ou eleitorais. O que muda é a intensidade com que se valoriza ou não cada fator. Professores e estudantes se afastam, também, na relevância que atribuem aos interesses econômicos, e os docentes se afastam mais da neutralidade do que os estudantes. Quando se comparam países, as mesmas tendências, nas respostas, são visíveis entre docentes e estudantes.

As razões mais frequentes destacadas por todos são as relacionadas com inovação científica e tecnologia e, em segundo lugar, as de ordem coletiva e econômica. Não é possível relacionar essa tendência com alguma corrente historiográfica contemporânea, nem em currículo. Embora a 
questão tecnológica esteja presente na literatura sobre ensino de História, não aparece no sentido aqui detectado.

\section{CONSIDERAÇÕES FINAIS}

Considerando que, de maneira geral, predomina no Brasil o que se costuma chamar de currículo editado (ESCOLANO, 2006 apud CAIMI, 2016), valeria a pena uma investigação aprofundada sobre os principais fatores de mudança descritos nos livros didáticos. Isto poderia ajudar a concluir se a homogeneidade nas respostas reflete tanto uma tendência que circula na sociedade em geral (hipótese), quanto uma tendência presente na história escolar editada, já que, certamente, não reflete uma escola historiográfica. Uma evidência desta afirmação é a baixa circulação da história ambiental, mesmo entre historiadores profissionais (PÁDUA, 2010), contraposta com a alta valorização do tema nas respostas de estudantes e de professores.

Embora à primeira vista se note continuidade nas respostas de estudantes e docentes sobre a conjuntura dos últimos 40 anos e na projeção dos próximos 40 anos, algumas questões parecem se destacar, como o crescimento da valorização do fator Problemas ambientais ou Poluição e o não reconhecimento da migração ou de lideranças religiosas como fatores influentes.

Segundo Rüsen (2015, p. 38), as pessoas percebem a história como "contingência como experiência do tempo", também "perturbação e supressão de sentido" (RÜSEN, 2015, p. 39), além de "humanização do tempo" ou "passagem do tempo natural ao tempo humano" (RÜSEN, 2015, p. 40). Esta passagem permite que contingência e perturbações ganhem sentido, pelo trabalho de interpretação.

É dessa maneira, nesse modo específico do trabalho interpretativo do espírito humano acerca das circunstâncias da vida de seus sujeitos, que a história entra no mundo. Ela não nasce do espírito humano; no entanto, só ganha seu caráter específico mediante seu trabalho com as experiências temporais que a pressionam (RÜSEN, 2015, p. 41).

As constatações aqui apresentadas exigem maior número de conexões entre os dados do projeto, ampliação de pesquisas qualitativas paralelas e maior apoio a teorias sobre explicações históricas e suas construções por parte dos jovens. As reflexões de Rüsen (2007) sobre os limites das 
explicações de tipo nomológico e intencional e as características das explicações de tipo narrativo são importantes, mas só poderiam apoiar se os dados utilizados fossem narrativos e não múltipla escolha. Quiçá a articulação entre o mapeamento dessas tendências e a análise de narrativas escritas seja um passo metodológico interessante a contribuir com o entendimento da construção de narrativas históricas por parte dos jovens.

Entretanto, é possível perceber que alguns tópicos são recorrentes, tanto entre professores quanto entre estudantes, na tentativa de atribuição de sentido à experiência da passagem do tempo e, notadamente, das mudanças sofridas.

Sentido se refere, de um lado, à sensibilidade do homem como porta de entrada da experiência, como entrelaçamento do espírito humano com o mundo em que se encontra; de outro lado, o sentido integra essa experiência do mundo no horizonte da determinação intelectual do agir e do sofrimento humanos. No íntimo do homem, sentido é o critério fundamental, com o qual o homem tanto regula sua relação para consigo mesmo e para com os outros, quanto decide sobre suas intenções e sobre a intencionalidade de sua vontade. Sentido torna possível a orientação. Ele situa a vida humana no horizonte das interpretações; torna o homem e o mundo compreensíveis; possui uma função explicativa; forma a subjetividade humana no construto coerente de um 'eu' (pessoal e social); torna o sofrimento suportável e fomenta o agir pelas intenções. Enfim, o sentido torna possível a comunicação como processo do entendimento intra-humano (RÜSEN, 2015, p. 42).

O sentido de tempo é importante quando se pensa que os sentidos que interessam aqui são os históricos, os temporais. Localizar os eventos no tempo é fundamental para a interpretação e, por sua vez, pode ter implicações diretas na constituição de identidades e na orientação para a ação humana. Ou seja, quando esses jovens e seus professores hierarquizam essas causas de mudança, constroem, também, balizas ao redor das quais deslizam possibilidades de agência histórica para si próprios e seus grupos.

Rüsen explica que a experiência histórica consiste no sofrer e agir dentro das mudanças temporais. A experiência de ruptura causa desequilíbrio, ou carência de orientação, a qual pode ser superada - ou interpretada - no encadeamento das mudanças. Ela tem um caráter desequilibrador e, em razão disso, pode orientar, no campo da cultura, a vida prática, por 
meio da problematização constante das identidades: "[...] a orientação possui uma relação direta com a vida prática [...] É aqui que o saber histórico tem uma das suas mais importantes funções de orientação: seu papel na formação, negociação, implementação e alteração de identidade" (RÜSEN, 2017, p. 47-48).

Tendo em vista que as identidades se constituem e se questionam, constantemente, pelos desequilíbrios temporais e pela relação dialética com os outros, a busca de sentido e de orientação pode motivar para a ação. É nesse aspecto da orientação cultural, temporal e identitária perante os desequilíbrios causados pela experiência da vida prática que Rüsen (2015) encontra indícios das funções práticas do saber histórico.

Assim, pode-se afirmar que a ponte que se lança entre as diferentes experiências de tempo é a História, que se expressa em forma de narração, é a forma humana de conferir sentido a eventos, desde que seja considerada sua temporalidade. A História sempre se narra em contextos sociais e tem caráter de comunicação. Sua utilidade, isto é, o quanto contribui para a orientação e, consequentemente, para a agência histórica, depende sempre desses contextos. Além disso, a tensão entre contingência e liberdade é elemento muito importante para o sentido, o que permite a conexão aqui estabelecida entre as opções e tendências políticas de estudantes e professores e os fatores de mudança que avaliaram.

A existência de uma continuidade nos fatores demonstra que os jovens e os professores localizam-se no tempo de uma forma muito semelhante, havendo coincidências na comparação entre os países. As expectativas de futuro desenham-se de forma interessante na comparação entre o que os estudantes projetam para suas vidas e para o conjunto do país. Nota-se coerência porque, embora projetem para si próprios uma boa vida, ao mesmo tempo em que constatam problemas em seu país, os estudantes mais pessimistas no panorama nacional são, também, os mais pessimistas no panorama individual, e acreditam muito pouco no esforço pessoal como fator de mudança. Com relação ao esforço pessoal, seria de se esperar que fosse um fator menos valorizado pelos docentes, tendo em vista sua tendência à esquerda? Ou será que, novamente, a identidade de professor e as questões educacionais e formativas suplantam o político e o historiográfico? 
Chama a atenção, ainda, a quase insignificante variação de posicionamento dos docentes de distintas convicções políticas, enquanto, entre os jovens, maior ou menor interesse por política implica em diferenças na valorização dos fatores de mudança. É difícil afirmar um significado para esta constatação. No mínimo, é preciso pesquisar mais sobre o assunto, mas, de certa forma, confirma-se algo que professores de História intuem por conta própria, ao observar seus próprios estudantes.

Por fim, são apenas parciais e intuitivas as ideias que se podem forjar sobre agência histórica dos jovens a partir das evidências oferecidas pelo questionário do Jovens e a História, tendo em vista que ele só permite constatar um lado da constituição de sentido, deixando em segundo plano as decisões tomadas pelos jovens ao se reapropriarem do do curso da vida, como afirma Rüsen (2015, p. 55):

$\mathrm{Na}$ atividade de constituição de sentido pela consciência histórica estão presentes dois elementos: um momento constitutivo do sofrer - as coisas do mundo próprio não acontecem como deveriam - e, simultaneamente, um momento constitutivo da liberdade - eu me reaproprio das coisas do meu mundo, interpretativamente e por meio do leme da significância previamente dada, de modo a poder controlar o curso da minha vida segundo critérios que valham como meus (RÜSEN, 2015, p. 55).

Nem estudantes, nem professores, independentemente de onde vivem ou como se posicionam politicamente, consideram que os movimentos sociais, as ações de trabalhadores, as revoluções, os políticos, os líderes ou o esforço pessoal sejam fatores fundamentais de mudança. É possível que tal compreensão reflita tanto elementos da cultura histórica quanto tendência na História ensinada. É difícil saber.

Entretanto, esta constatação indica a necessidade de se prestar mais atenção na forma como as narrativas históricas e os fatores de mudança têm sido expressos no conhecimento histórico escolar veiculado nas aulas de História e construído por estudantes e professores. Haverá implicações pedagógicas derivadas dessa constatação? Ao que parece, a expressão corrente de que os jovens não se enxergam como sujeitos da história corresponde, também, aos docentes. Se a teorização de Rüsen sobre consciência 
histórica está adequada, então, poder-se-ia tensionar o ensino de História nas escolas de maneira estimular a orientação para a ação?

Assim como percebido em diversas outras perspectivas sobre o ensino de História, a ideia é deslocar o centro da aula de História da transmissão de conteúdos para o pensar historicamente e, neste, dedicar-se mais aos elementos finais em que o cognitivo, o ético e o estético conjugam-se para construir novas narrativas. Pode-se pensar em um esforço maior, por parte dos docentes e dos materiais didáticos, em retomar as problematizações iniciais, que mobilizaram o pensamento histórico, e construir situações didáticas em que os estudantes não apenas teorizem, mas tenham de extrapolar seus conhecimentos para situações de tomada de decisões e de proposições diversas.

Outra implicação pedagógica dessas constatações diz respeito à maneira como os textos didáticos explicam as mudanças acontecidas. Quem são os sujeitos que se apresentam como atores das mudanças? Os textos demonstram as possibilidades que foram ensaiadas, mas que, por diversas razões, foram sufocadas ou se desmobilizaram pelo caminho? As mudanças são apresentadas de maneira teleológicas? Entes como $a$ primeira guerra mundial ou a questão militar são mostrados como agentes de mudança? Evidentemente, diversos trabalhos já exploraram as falhas de livros didáticos nesse sentido. Entretanto, aqui se trata não apenas de verificar incorreções historiográficas ou pedagógicas, mas de construir narrativas históricas, na escola, que estejam atentas à orientação para a ação.

A partir deste recorte de pesquisa, fica o convite de seguirmos o debate sobre aulas de História que possibilitem analisar as muitas maneiras pelas quais as mudanças aconteceram e as diversas formas de explicá-las, bem como as implicações desses saberes sobre os questionamentos do presente e os dilemas que atravessamos ou pelos quais somos interpelados.

\section{REFERÊNCIAS}

BAROM, Wilian C.C. Integração latino-americana e consciência histórica: a noção de pertencimento latino-americano de jovens brasileiros no ano de 2013. 2017. 253f. Tese (Doutorado em Educação). Programa de Pós-Graduação 
em Educação. Universidade Estadual de Ponta Grossa. Ponta Grossa, 2017. Disponível em: <http://bicen-tede.uepg.br/tde_busca/arquivo. php?codArquivo=1780 > Acesso em: 15 jul. 2017.

CAIMI, Flavia E. A história na Base Nacional Comum Curricular: pluralismo de ideias ou guerra de narrativas? Revista do Lhiste. Porto Alegre, n.4, v.3, p.86-92, jan./jun. 2016. Disponível em: <seer.ufrgs.br/index.php/ revistadolhiste/article/download/65515/39462> Acesso em: 18 abr. 2017. CERRI, Luis Fernando. Dados quantitativos na reflexão didática de estudantes e professores de História. Revista História Hoje, São Paulo, v.5, n.10, p.138-158, 2016. Disponível em: <https://rhhj.anpuh.org/RHHJ/ article/view/272> Acesso em: 15 jul. 2017.

PACIEVITCH, Caroline. Responsabilidade docente: utopias de professores de história. Curitiba: Appris, 2014.

PÁDUA, José Augusto. As bases teóricas da história ambiental. Estudos Avançados. São Paulo, v.24, n.68, 2010. Disponível em: <http://www. scielo.br/scielo.php?pid=S0103-40142010000100009\&script $=$ sci_ arttext\&tlng=es> Acesso em: 18 abr. 2017.

PAIM, Elison Antonio. Memórias e experiências do fazer-se professor. 2005. 532 f. Tese (Doutorado em Educação) - Universidade Estadual de Campinas, Campinas, 2005. Disponível em: <http://libdigi.unicamp.br/ document $/$ ?code=vtls000379547>. Acesso em: 23 fev. 2012.

RÜSEN, Jörn. Teoria da História: uma teoria da história como ciência. Curitiba: Editora UFPR, 2015.

RÜSEN, Jörn. História viva. Teoria da História III: formas e funções do conhecimento histórico. Brasília: Editora da Universidade de Brasília, 2007. SOARES, Olavo Pereira. A atividade de Ensino de História: processo de formação de professores e alunos. Araraquara, SP: Junqueira \& Marin, 2008. 